\section{The relation between lisping and visual recognition memory in children*}

\author{
ROBERT G. CROWDER and KENNETH L. DAVIS† \\ Yale University, New Haven, Connecticut 06510
}

It was argued that if silent reading involves articulatory coding then children with a pronounced lisp ought to code two visual nonsense words such as RETH and RESS more similarly than children without a lisp. This, in turn, would lead to more false positives in a recognition memory task. Although the data confirmed this hypothesis, it turned out that lisping children made more correct positives (hits) as well. Lisping and normal children did not differ in sensitivity $\left(d^{\prime}\right)$; therefore, the main result was a difference in criterion. An implausible hypothesis was offered so as to salvage a portion of the original argument.

This report offers a preliminary attempt to relate lisping, an ostensibly peripheral articulatory disorder, to visual recognition memory, an ostensibly central form of information processing. In view of the acute communicative and social difficulties which attend persistence of lisping into middle childhood, it is more than understandable that primary research attention has gone to teasing out the proximal cause of the disorder and especially to the development of effective corrective programs (e.g., Karlin, Karlin, \& Gurren, 1965). Serving these objectives is a large body of data and theory covering the role of the tongue in lisping (Ronson, 1965) and covering therapeutic procedures oriented towards the tongue (Luchsinger \& Arnold, 1965). One exception to this marked peripheral emphasis in lisping research is a group of studies relating articulatory defects to auditory speech discrimination (see Prins, 1963, and references therein). The value of looking for receptive as well as expressive problems in articulatory defectives is obvious when contemporary theories of information processing are taken into account. There is agreement among several models of speech perception (Liberman, Cooper, Shankweiler, \& Studdert-Kennedy, 1967; Morton \& Broadbent, 1967 ; Neisser, 1967-theories which are otherwise in sharp disagreement) that articulatory coding plays a central role in sorting out and categorizing speech sounds. Data showing the predicted correlation between input and output disorders (Prins, 1963; Weiner, 1967) carry a double payoff. They jointly strengthen the information-processing models on which they are based and give the therapist a more complete picture of the problem he faces than do

*This research was supported by NSF Grants GB 4066 and GB 15157.

+Now at the Mt. Sinai School of Medicine, New York, New York 10029. investigations of the technological aspects of speech correction alone.

The present research extends this type of analysis further in seeking correlates of articulatory disorders with visual cognition. The background comes in part from Conrad's (1964) discovery that errors in immediate memory are based on phonic similarity, even when presentation is visual and recall written. That is, when the letter $B$ is misrecalled in a series of consonants $\mathbf{S}$ has just seen, he is more feels) like $B$, than $S$. One interpretation which has been placed on such data (Crowder \& Morton, 1969; Hintzman, 1967) is that visually presented language units (as well as aural speech) undergo at some stage a coding in terms of articulation (although see Wickelgren, 1969). A general implication of these notions has been empirically tested by Conrad and Rush (1965) in a nonnormal population (although these authors assumed it was auditory rather than articulatory imagery involved in visual memory). Conrad and Rush showed that in subpopulations of hearing and deaf adolescents with similar overall scores, errors were related to phonic features only for the normal Ss.

Consider a simple recognition-memory task in which five nonsense words are exposed visually in sequence. On each trial $\mathbf{S}$ has to make a yes-no decision concerning whether the last word presented is identical to one of the earlier four. On positive trials a repetition is built into the sequence, but on negative trials all five words are different. Primary interest is in a certain class of negative trials wherein the final (test) word terminates either in $|\theta|$ or $/ s \mid$ (e.g., WOSS), and wherein one of the earlier four words was identical except for a change of $/ \theta /$ to $/ \mathrm{s} /$ or vice versa (e.g., WOTH). If the list had originally been encoded in terms of articulatory features and if $|\theta|$ and $|s|$ are functionally equivalent for lispers, likely to give $V$, which sounds (and then lispers should be more inclined than normals to report that a repetition had occurred on that list. On other negative trials not incorporating this particular pair of sounds, however, there should be no difference between lispers and normals. These were the basic predictions for the present study. Note that $S$ is never required to speak the materials; he need only say yes or no after each list.

There is a small literature on comparisons of memory performance between normals and articulatory defectives. Conclusions drawn from these studies range from acceptance of the null hypothesis (Hall, 1944) to inconclusive differences (Metraux, 1944; Robbins, 1942). The present research differs from this prior research in using exclusively visual presentation, in requiring unobtrusive recognition responses rather than whole recall, and in using specially prepared stimulus materials designed to selectively tap the articulatory disorder.

\section{PROCEDURE}

Subjects

Thirty-two children of both sexes served as Ss. These were divided into four subgroups of eight on the basis of articulation (lispers vs normals) and grade (third vs fourth and fifth). Fourteen were from the Milford Connecticut public school system and 18 were from the Syosset New York public school system. 1 Both communities are socioeconomically upper-middle class.

The 16 lispers were selected by the schools' speech therapists as being frontal lispers with varying degrees of lingual protrusion; lateral lispers were not included in the sample. All of these articulatory defectives had been in therapy for from 1 to 5 years. Finally, all were judged by $\mathbf{E}$ to have an obvious lisping problem, whereas none of the control Ss did.2 The 16 control Ss were judged by the schools' speech therapists to have normal articulation based on a standardized test administered at the beginning of the term. These control Ss were selected jointly by the therapist and the teachers to be roughly matched for IQ, reading level, and word attack skills.

In the entire sample of 32 there were equal numbers of males and females, 316 third graders, 10 fourth graders, and 6 fifth graders.

\section{Method and Design}

Following a few general remarks and establishment of rapport, $\mathbf{S}$ was given a short memory-span type of task involving 12 trials of consonant series varying in length from two to 
Table 1

Examples of Tril Strueture

\begin{tabular}{|c|c|c|c|c|}
\hline \multirow{2}{*}{$\begin{array}{c}\text { Repetition } \\
\text { Structure }\end{array}$} & \multicolumn{4}{|c|}{ Articulatory Designation } \\
\hline & Confusing & Nonconfusing & Preudo & nfusing \\
\hline Positive & $\begin{array}{l}\text { FOPS } \\
\text { FITH } \\
\text { SEMP } \\
\text { CALK } \\
\text { FITH }\end{array}$ & $\begin{array}{l}\text { CALK } \\
\text { SHAN } \\
\text { GAKE } \\
\text { SEMP } \\
\text { SHAN }\end{array}$ & & \\
\hline Negative & $\begin{array}{l}\text { VONG } \\
\text { WOSS } \\
\text { STAP } \\
\text { HENT } \\
\text { WOTH }\end{array}$ & $\begin{array}{l}\text { PREP } \\
\text { RETH } \\
\text { SIRI } \\
\text { LOME } \\
\text { MURR }\end{array}$ & $\begin{array}{l}\text { FISS } \\
\text { LOME } \\
\text { HENT } \\
\text { SIRL } \\
\text { RETH }\end{array}$ & $\begin{array}{l}\text { ROON* } \\
\text { WOTH } \\
\text { CALK } \\
\text { FOPS } \\
\text { LUTH }\end{array}$ \\
\hline
\end{tabular}

*Half of the pseudoconfusing trials contained the $/ 8 /-10 /$ pat (FISS-RETH) and half contained the $/ 8 / / 4$ or $/ \theta /-/ \theta /$ paire (WOTH-LUTH).

seven items. Presentation was visual and recall, oral. These data were used to permit establishment of comparability between groups in memory ability.

The main task consisted of 96 trials on which five nonsense words were presented. The words were printed in block letters on $5 \times 8$ in. cards and presented manually for about 1 sec each. No limit was placed on response times.

Eight nonsense words were developed specifically to carry high potential confusability for lispers; arranged in pairs, they were FI TH - F I S S, RETH-RESS, LUTH-LUSS, and WOTH-WOSS. Sixteen other words were intended not to carry such pairwise confusability: CALK, FOPS, LOME, SEMP, HENT, SIRL, VONG, STAP, ROON, SHAN, GAKE, DATS, MURR, TEEL, RETS, and PREF. Within the constraints imposed by having to set up the various experimental conditions described below, the occurrence and order of words used on a trial was determined randomly.

Table 1 illustrates the various kinds of word lists with which $S$ was faced during the experiment. On positive trials the fifth word matched exactly one of the first three and on negative trials it did not. On positive confusing trials, one of the eight potentially confusing words was presented twice; on negative confusing trials both members of one of the confusing pairs were used. On nonconfusing trials, any word could be used; however, of course only one from the confusing set was allowed to occur. A third category of trials was designated

Table 2

Falce Alarms: Percent "Yes" Responces on Nerative Trials

Group

\begin{tabular}{lccccc}
\hline & \multicolumn{4}{c}{ Group } \\
\cline { 2 - 3 } \cline { 5 - 6 } Item Type & Lispers & Controls & & Lispers & Controls \\
\cline { 2 - 3 } \cline { 5 - 6 } & Tourd Grade & & Fourth-Fifth Grade \\
\hline Conconfusing & 10.3 & 10.4 & & 9.3 & 8.4 \\
Confusing & 49.4 & 35.4 & & 38.7 & 25.0 \\
\hline
\end{tabular}

"peeudoconfusing." On these, one of the eight potentially confusing words appeared in the final (test) position with prior exposure on the same trial of a word ending in one of the critical sounds $(/ s /$ or $/ \theta \mid)$ but with a different pair of initial letters; these were intended to prevent $S$ from paying attention only to the last two letters in each word. Naturally, there could be no positive pseudoconfusing trials.

There were 48 confusing trials, 24 each positive and negative. There were 24 nonconfusing trials, 12 each positive and negative. All 24 of the pseudoconfusing trials were negative. Thus, perfect performance demanded saying "no" 60 times and "yes" 36 times. Conditions were systematically distributed across the 96 trials so as to be locally irregular but well balanced over practice.

\section{RESULTS}

Performance on the

Memory-Span Pretest

The pretest involved series of consonant letters of varying lengths. The performance measure used was, for each $S$ separately, the number of failures to recall a letter in its correct position (maximum = 54). Among the third graders, the lispers had a mean of 20.4 errors and the controls a mean of 25.5 errors. Among the fourth and fifth graders, the lispers had a mean of 17.9 errors and the controls a mean of 18.3. A 2 by 2 factorial analysis of variance on these data revealed that the difference between lispers and controls (a difference which favored the lispers) was nonsignificant, $F=1.09$. Thus children improve with age in immediate memory, as was to be expected, but lisping is accompanied by no apparent general memory deficit.

\section{False Alarms}

The main prediction of the experiment was that on negative trials (i.e., trials with no repetition) lispers would be more inclined to say "yes" (a false alarm) than controls when a confusing pair had occurred but not otherwise. The relevant means are given in Table 2. The findings were that, whereas all groups performed about equally on nonconfusing trials, there was a greater false alarm rate for lispers than for controls on confusing trials and also, on the latter items, an improvement with age. Analysis of variance confirmed the reliability of this summary. The only statistically significant main effect was that due to trial type, $F(1,28)=107.5$, $p<.01$, indicating better overall performance on the nonconfusing items. The interaction of group (lispers vs controls) with trial type, $F(1,28)=4.70, \quad p<.05$, directly confirmed the main hypothesis. A separate rank-8ums test performed for confusing trials alone showed a highly significant difference between lispers and controls, $T^{N}=201, p=.009$ (based on transformation of ' $\mathrm{T}^{\prime}$ to $\mathrm{z}$ ). The only other statistically significant interaction was that of age with trial type, $F(1,28)=5.13, p<.05$, indicating that older $\mathrm{Ss}$ made fewer false alarms than younger $\mathrm{Ss}$, but only on confusing trials.

It is hard to imagine how the data on faise alarms could more strongly have confirmed the initial hypothesis. However, for reasons to be taken up presently, these data give a seriously misleading picture. The foregoing analysis is misleading mainly because it takes no account of behavior on positive trials. The problem is conveniently brought out by reference to statistical decision theory (Swets, 1964). According to a decision-theory analysis of recognition, $S$ is presented on each trial with evidence from his memory about whether a repetition occurred-evidence which is always to some extent mixed. Based on this mixed evidence $S$ is thought to do two things: (1) determine the likelihood of a repetition, and (2) decide what response to make (i.e., yes or no). The S'B subjective estimate favoring a

Table 8

Hits: Pereent "Yes" Responses on Posittve Triale

\begin{tabular}{|c|c|c|c|c|}
\hline \multirow[b]{3}{*}{ Item Type } & \multicolumn{4}{|c|}{ Group } \\
\hline & \multicolumn{2}{|c|}{ Thtrd Grade } & \multicolumn{2}{|c|}{ Fourth-Fifth Grade } \\
\hline & Lispert & Controls & Lispers & Controls \\
\hline $\begin{array}{l}\text { Noncontusing } \\
\text { Confusing }\end{array}$ & $\begin{array}{l}82.3 \\
81.8\end{array}$ & $\begin{array}{l}79.2 \\
67.4\end{array}$ & $\begin{array}{l}81.1 \\
82.5\end{array}$ & $\begin{array}{l}84.4 \\
75.4\end{array}$ \\
\hline
\end{tabular}


repetition will be related to the quality of his memory for the stimulus, while his decision about what response to make is assumed to depend not only on memory but also on S's propensity for making certain kinds of errors (viz, saying a repetition occurred when it had not or saying a repetition had not occurred when it had). Stages 1 and 2 of the recognition process are assumed to be related by the setting of a "criterion" (in terms of odds-favoring-repetition) beyond which S says "yes" and short of which $S$ says "no." The criterion can vary independently of the ability to detect repetition; it is an index of how reckleas $S$ is willing to be in accepting evidence for repetition as conclusive. From this, it is clear that any observed value for false alarms is of necessity fixed by two processes, S's ability to detect repetition and his willingness to accept narrow odds as conclusive. A difference between two groupe in the false alarm rate, likewise, could be attributable to a difference in sensitivity, a difference in criterion, or both. Thus, going back to the data of Table 2, it is seen that lispers say "yes" more often than controls on negative confusing trials. But what if they were also saying "yes" more often than controls when a repetition involving these confusing words did occur? The following analyses show this to have been the case in the present study.

Decision-Theoretic Analyses

Table 3 gives the percentage of hits for the various experimental conditions (i.e., of "yes" responses when a repetition had in fact occurred). As was the case for the false alarm data (Table 2), performance was essentially constant on trials where the confusing word pairs were not presented. However, on confusing trials, the lispers achieved a larger rate of hits than did the controls. Thus, the lispers not only said yes too often when it was inappropriate, they also said yes more frequently than the controls when they should have. In the analysis of variance associated with the data of Table 3, this finding showed up as a statistically significant interaction of group (lispers vs controls) with trial type, $F(1,28)=4.22, p<.05$. Taking the confusing trials alone, the superiority of lispers to controls was confirmed by a rank-sums test, $T^{*}=198.5, p=.007$. No other statistical effect reached reliable levels for these data. Note that there were age-related differences in Table 2 for false alarms but not in Table 3 for hits.

Thus, whatever they remembered about items on confusing trials, the lispers required less evidence to assert that a repetition had occurred than did the controls. The next analytic question is how to distinguigh this greater recklessness of the lispers than of the controls (i.e., their lower criterion for accepting mixed evidence as conclusive) from the groups' respective abilities to distinguiah repetition trials from nonrepetition trials. Given certain underlying

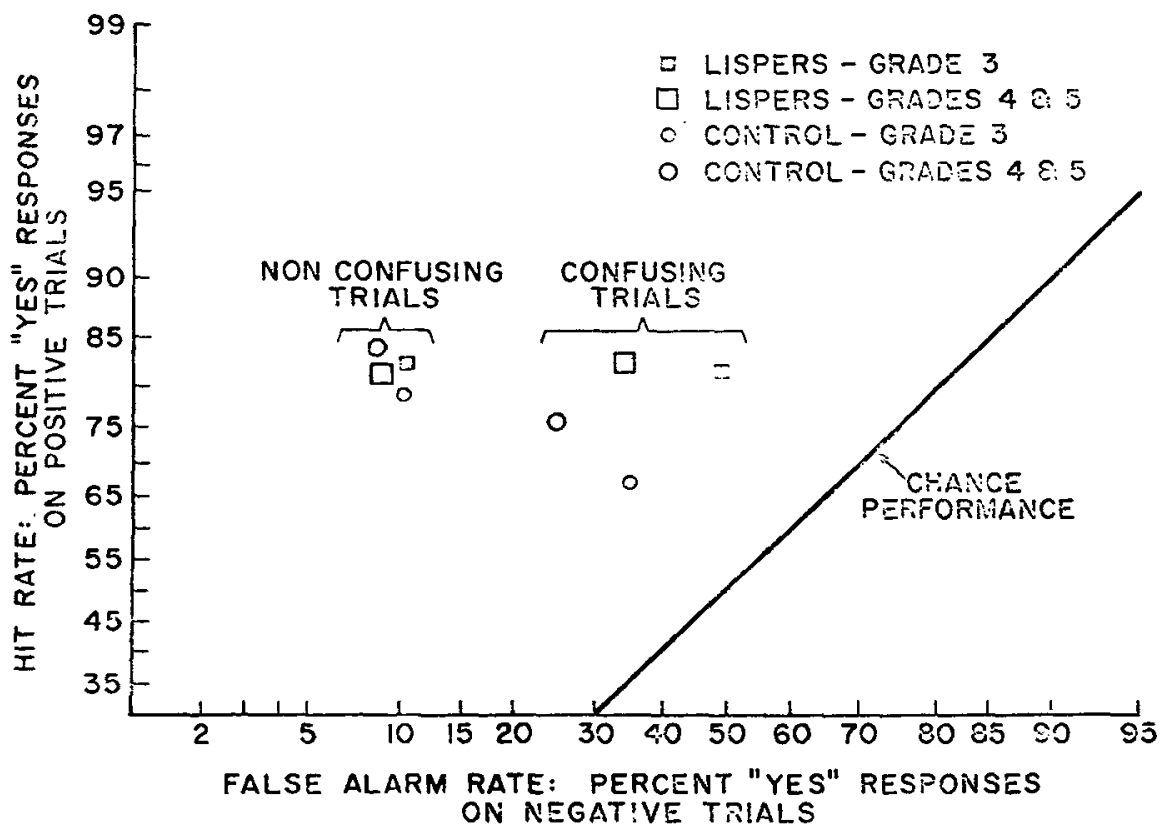

Fig. 1. Joint plotting of hits and false alarms as functions of the treatment combinations. Normal probability scale. assumptions (ree Swets, 1964), this distinction is accomplished graphically by the receiver (or memory) operating characteristic, wherein each group's hits are plotted as a function of their false alarms. Figure 1 gives such a representation of the data from Tables 2 and 3. Chance performance (as would be obtained if on every trial $S$ flipped a coin to decide on a positive or negative response) lies along the major diagonal. Departures from the chance line towards the upper left represent increasingly correct discrimination of repetition from nonrepetition. Variation of points in the other direction, i.e., in distance between the lower-left and upper-right corners, reflect no differences in memorial acuity but rather differences in criterion. Points toward the lower-left corner indicate conservative criteria and points toward the upper-right corner indicate reckless criteria. A single parameter, called d', or sensitivity, can be derived for a point on the receiver operating characteristic representing its distance from the chance diagonal, a theoretically pure measure of how well positive and negative trials were being distinguished. Table 4 shows d' values for the various treatment combinations (the larger $d^{\prime}$, the better performance). Analysis of variance on the data of Table 4 showed trial type to be the only significant source of variation, $F(1,28)=42.1, p<.01$. Thus for all ages and groups it was easier to distinguish repetition trials from nonrepetition trials when there was not a confusing word pair. In Fig. 1 this shows up as the farther position of all the points for nonconfusing trials from the chance diagonal than of all the confusing-trial points. Although the analysis of variance gave no statistically significant effect related to age, it is apparent from Fig. 1 that older $\mathbf{S}$ had a larger d' than younger Ss on confusing trials. Since this finding was not confirmed by the overall analysis, the significant rank-sums test for this comparison, $T^{\prime}=212, p=.025$, must be taken with some caution.

The main result given by Table 4 and Fig. 1 is that lispers and controls were equally proficient in distinguinhing positive and negative confucing trials. It will be noted for these data that the lispers' points are convistently (i.e., at both ages) displaced towards the direction of a more lenient criterion. Given the significant differences between lispers and controls for both hits and false alarms, it is a logical necessity that this criterion difference between groups be a reliable one. Only when confusing trials occurred were the lispers more reckless than the controls in claiming to have seen a repetition. 


\section{DISCUSSION}

The assumption underlying this research was that verbal materials are categorized through and stored by an articulatory code, even when presented silently and stored without vocalization. From this it follows that individuals with a central articulatory deficit would encode certain critical items nonveridically, such as WOTH and WOSS, which ought to have been functionally equivalent for lispers. $T h i s$ hypothesized functional equivalence of confusable pairs would lead to enhanced false alarm rates in the repetition-detection experiment. From this reasoning, there was no case to be made for changes in hit rates or for trials not containing a confusable pair.

The data from the present experiment reveal this argument to be inadequate. True, lisping did selectively affect performance on confusing trials; however, the process affected was not discrimination of repetition from nonrepetition but rather the Ss' conservatism-leniency in assigning positive responses to ambiguous evidence. Clearly if WOSS and WOTH were functionally equivalent for lispers, the finding would have been reduced $d^{\prime}$.

The present data permit only speculation about the mechanism which produced criterion differences on confusing trials. The range of permissable speculation is somewhat reduced by the data for pseudoconfusing trials (see Table 1), trials where words from the confusing list were used, but repaired so as to have different initial letters (RESS-WOTH). It might have been supposed that merely seeing one of the confusing words during a trial would have "alerted" lispers to the special feature of confusing trials and that at such a point they would have somehow adjusted their behavior in a way that normals did not. However, since pseudoconfusing trials contained the same critical words in one of the first three positions, the alerting should have led to increased false alarms for them as well as for true confusing trials. This was not the case, nor were there any reliable intergroup differences for pseudoconfusing trials. Thus, the criterion effect of lisping on confusing trials must not have been caused by simply seeing one confusing word, but rather by the conjunction of two confusable words on a particular trial. Stated differently, this means that whatever lispers did on confusing trials occurred after all evidence on a trial was in (i.e., all five words); they did not change their strategy once any critical item appeared.

A lenient or reckless criterion (such as was here adopted by the lisping

Table 4 Mean $a^{\prime} \mathbf{V}$ alues

\begin{tabular}{lccccc}
\hline & \multicolumn{3}{c}{ Group } \\
\cline { 2 - 5 } Item Type & \multicolumn{2}{c}{ Third Grade } & & Fourth-Fifth Grade \\
\cline { 2 - 5 } & Lispers & Controls & & Lispers & Controls \\
\hline Nonconfusing & 2.54 & 2.62 & 2.67 & 2.87 \\
Confusing & 1.07 & 0.94 & 1.53 & 1.57 \\
\hline
\end{tabular}

group) will be set if (1) hits have unusually high value, or (2) misses (saying no when a repetition had actually occurred) have an unusually high cost. Either (1) or (2) could have led lisping $\mathrm{Ss}$ to selectively use a lenient criterion on confusing trials. On the face of it, however, the reinforcement contingencies of speech therapy would more plausibly appear to bias costs and payoff in the opposite direction. One might have supposed, for example, that awareness of their speech problem would have set lispers to be unusually wary of the $|s|-|\theta|$ confusion, a wariness which would lead to conservatism in assertine identity among confusing words. Artificial manipulation of costs and payoffs is rather easily accomplished in experimental situations (by either instructions or by tangible incentives), so it should be possible in future research to examine these influences directly.

A second class of determinants of the criterion (besides costs and payoffs) is the relative frequency with which the two critical events, in this case repetition and nonrepetition, occur. Other things equal, $\mathbf{S}$ will adopt a lenient criterion when the event to be detected is perceived as relatively frequent; he will adopt a stringent criterion when the event is perceived as relatively infrequent. Now, of course, the objective frequencies of repetition and nonrepetition on confusing trials were equal for all $\mathrm{Ss}$ in the present experiment, so any argument involving this type of influence on the criterion has to depend on unrealistic subjective frequency estimates. An argument of this sort follows. Though admittedly far-fetched, it is an argument that both rescues something of the original hypothesis and at the same time appears more promising than the cost-payoff approach.

The main assumption is that different forms of coding are used by lispers (and other $\mathrm{Ss}$ as well) in (1) deciding whether repetition occurred on a particular trial, and (2) estimating overall frequencies of repetition and nonrepetition during the experimental session. This would happen if the former code were transient (e.g., visual image) and the latter more permanent (e.g., articulatory). Assuming that Ss can distinguish confusing from nonconfusing trials and that different criteria can be employed for the trial types (which assumption is, of course, confirmed by the data for lispers), then the following scenario could represent what happened: All S\&, when a confusing trial occurs, estimate the odds favoring repetition through a visual (or some other nonarticulatory) matching process. Once these odds are established, a criterion is applied to determine whether the odds are sufficiently long to merit a "yes" response. For normals, criterion placement is based on a relatively accurate tally of how many prior trials involving confusing words have been positive and how many have been negative. For lispers, however, the only type of evidence about what prior confusing trials have been like is articulatory evidence. This articulatory evidence for lispers is nonveridical in that confusing pairs are remembered as identities. Thus, lispers overestimate the relative frequency of positive trials for lists containing confusing pairs. This overestimation in turn dictates use of a lenient criterion. On nonconfusing trials, however, the lispers and controls are both able to use veridical evidence (evidence based on articulatory cues which maintain distinctions among items) in their frequency estimates and therefore perform indistinguishably. Posner, Boies, Eichelman, and Taylor (1969) have provided evidence that visual information can survive delays on the order of seconds, so the use of visual information in local responding by these $\mathrm{Ss}$ is not completely implausible. If such visual coding later gave way to articulatory coding, then the original hypothesis offered in the present report could have been true of the long-term performance but not true of the short-term performance. Since $d^{\prime}$ measures used here came entirely from the short-term (within a single trial) responding, the disconfirmation of the original reasoning is quite understandable.

Although the scenario proposed above is pure speculation, it should be remembered that the criterion change observed must reflect either (1) difference between lispers and normals in relative-frequency estimation, or (2) different subjective costs and payoffs for trial outcomes. 
The former has been favored because no plausible cost-payoff changes appeared possible. Fortunately, both alternatives (1) and (2) are testable. Through instructions it is possible to fix artificially the costs and payoffs governing criterion setting, as has been observed above. The hypothesis that coding for long-term performance suffers from articulatory confusions among lispers is testable by using a recognition task where the lag between presentation and testing is lengthened sufficiently to preclude survival of visual information. Until these possibilities are checked, it is imprudent to speculate on the meaning of these results for information-processing theory or for treatment of lisping.

\section{REFERENCES}

CONRAD, $R$. Acoustic confusions in immediate memory. British Journal of Psychology, 1964, 55, 75-84.

CONRAD, R., \& RUSH, M. L. On the nature of short-term memory encoding by the deaf. Joumal of Speech \& Hearing Disorders, 1965, 30, 336-343.

CROWDER, R. G., \& MORTON, J. Precategorical acoustic storage (PAS). Perception \& Psychophysics, 1969, 5, 365-373.

HALL. M. Auditory factors in functional articulation defects. Journal of Speech \& Hearing Disorders, 1944, 9, 347-355.

HINTZMAN, D. L. Axticulatory coding in short-term memory. Journal of Verbal Learning \& Verbal Behavior, 1967, 6 . 312-316.

KARLIN, 1. W., KARLIN, D. B., \& GURREN, L. Development and dioorders of speech in childhood. Springfield, III: Charles C Thomas, 1965.

LIBERMAN, A. M., COOPER, F. s.. SHA N K W E I L R, D. P.., STUDDERT-KenNedY, M. Perception of the speech code. Paychological Review, $1967,74,431-461$.

LUCHSINGER, R., \& ARNOLD, G Voice-speech-language. (Trans. G. Arnold \& E. R. Kinkbeiner) Belmont. Calif: Wadsworth, 1965. Pp. 564-583.

METRAUX, R. Auditory memory span for speech sounds. Journal of Speech \& Hearing Disorders, 1944, 9, 28-31.

MORTON, J., \& BROADBENT, D. E Pasalve versus active recognition models ox, Is your homunculus really necessary? In W. Wathen-Dunn (Bd.), Models for the perception of speech and visual form. Cambridge, Mass: MIT Press, 1967.

NEISSER, U. Cognitive psychology. New York: Appleton-Century-Crofts, 1967.

POSNER, M. I., BOIES, S. J. EICHELMAN, $w$. Retention of visual and name codes of single letters. Journal of Experimental Psychology Monograph, 1969, 79(1, Pt. 2), 1-16.

PRINS, D. Relations among specific articulatory deviations and responses to a clinical measure of sound discrimination ability. Journal of Speech \& Hearing Disorders, 1963, 28, 382-388.

ROBBINS, D. P. Importance of sensory training in speech therapy. Journal of Speech \& Hearing Disorders, 1942, 7, 18 3-188.

RONSON, I. Incidence of visceral gwallowing among lispers. Joumal of Speech \& Henring Disorders, 1965, 30, 318-324.

SWETS, J. A. Signal detection and recognition by human observer: Contemporary neadings. New Yox: Wiley, 1964 .

WEINER, P. S. Auditory discrimination and articulation. Journal of Speech \& Hearing Disorders, 1967, 32, 19-28.

WICKELGREN, W. A. Auditory or articulatory coding in verbal short-term memory. Psychological Review, 1969, 76 , 232-235.

\section{NOTES}

1. We wish to thank Richard Irwin of the Milford Public Schools and Phillip Allespens of the Syomett Public Schools for their cooperation in screening of $\mathrm{Ss}$ and in providing research space.

2. Two $\mathrm{Ss}$ were eliminated from the oririnal sample and replaced. One child who had been suggested as a lisper was judsed by $E$ to have no apparent lisp, and one norma turned out actually to possess a lisp. For all Ss ultimately included in the analysis, it was therefore true that $\mathrm{E}$ and the speech therapist were in perfect asreement about presence or absence of the disorder.

3. Due to the relative scarcity of "good" lispers, the mixture of males and females in each of the Articulation by Grade subgroups was not identical; however, there was no apparently systematic bias in the sampling and furthermore there was no evidence for sex differences in the results.

(Accepted for publication October 28, 1971.) 